\title{
Diagnosis and Long-term Management of Uromodulin Kidney Disease
}

\author{
Emily Wheeler ${ }^{1}$, Suresh Thomas ${ }^{1}$ \\ 1. Internal Medicine, West Virginia University School of Medicine, Morgantown, USA
}

Corresponding author: Emily Wheeler, eaw0010@mix.wvu.edu

\begin{abstract}
Uromodulin kidney disease (UKD) is a subtype of autosomal dominant tubulointerstitial kidney disease (ADTKD), and is a rare cause of renal failure and gout in young people. Although it is inherited in an autosomal dominant fashion, the gene mutation exhibits variable expressivity so the phenotype varies dramatically among affected individuals. While it is rare, it is important for physicians in the primary care setting to be able to recognize the disorder, initiate proper workup, and refer patients to nephrology teams that are equipped to manage the long-term needs of these patients. Eventually, most will progress to renal failure with necessary renal dialysis or kidney transplant. Kidney transplant is curative as the new kidney does not have the defective tubule cell gene. The case series that follows highlights the variable presentations of the disorder among members of the same family and the necessary long-term follow-up that will often be handled by the primary care provider in conjunction with the specialist team.
\end{abstract}

Received 02/04/2019

Review began 02/07/2019 Review ended 03/16/2019 Published 03/19/2019

\section{() Copyright 2019}

Wheeler et al. This is an open access article distributed under the terms of the Creative Commons Attribution License CC-BY 3.0., which permits unrestricted use, distribution, and reproduction in any medium, provided the original author and source are credited.
Categories: Family/General Practice, Internal Medicine, Nephrology

Keywords: uromodulin kidney disease, familial juvenile hyperuricemic nephropathy, autosomal dominant tubulointerstitial kidney disease, gout, renal failure, end stage renal disease, esrd (end stage renal disease)

\section{Introduction}

Autosomal dominant tubulointerstitial kidney disease (ADTKD) is a group of three rare genetic diseases that share a common feature of slowly declining kidney function starting in adolescence or young adulthood and leading to end-stage renal disease (ESRD). Other features common to all three subtypes include: bland urine sediment with signs of chronic kidney disease (CKD) and the possibility of renal medullary cysts. The most common subtype is uromodulin kidney disease (UKD) caused by mutations in the uromodulin (UMOD) gene that encodes uromodulin (Tamm-Horsfall protein). Defective uromodulin cannot be exported and so accumulates inside renal tubule cells and leads to cell death. UKD is also characterized by hyperuricemia and early-onset gout, although these may not be seen in all patients with this genetic subtype. The second subtype is Mucin-1 kidney disease (MKD) caused by mutations in the MUC1 gene that causes renal failure without other specific findings. The rarest form is caused by renin (REN) mutations (ADTKD-REN) and is characterized by anemia in childhood, hypotension, mild hyperkalemia, and hyperuricemia [1].

\section{Case Presentation}

This report follows members of a family with documented UKD (Figure 1).

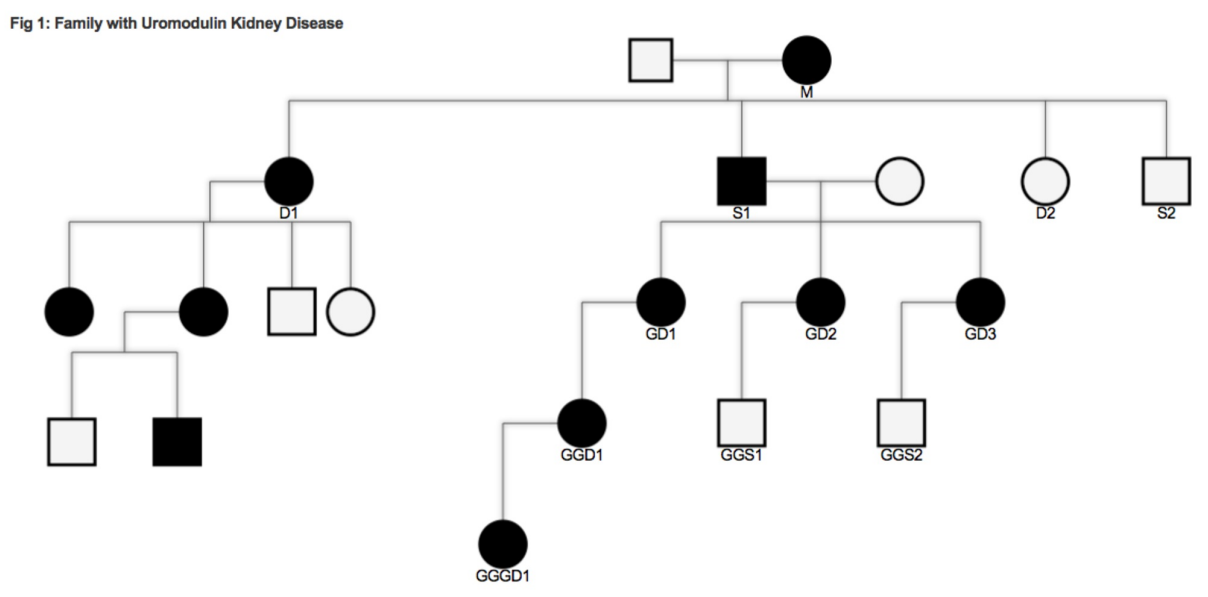

FIGURE 1: Family with uromodulin kidney disease

M: Mother, S1: son, D1: daughter, GD1/2/3: granddaughter 1/2/3, GGD1: great-granddaughter, GGGD1: greatgreat-granddaughter 
Patient S1 had gout and refractory hypertension for many years before being clinically diagnosed with a genetic kidney disorder in 1975. His mother (M), who is thought to have carried the UMOD mutation as well, had hypertension without gout and died at the age of 86 years. One of his sisters (D1) was also diagnosed with the disorder but little information about the clinical onset of disease in her family is available. In 1978, his three children (granddaughter (GD)1, 2, and 3) were tested and diagnosed using urine analysis and serum uric acid and creatinine levels. When it became available, genetic testing was done on two members of the family (GD2, great-granddaughter (GGD1)) and it found UMOD gene mutations. The table describes the clinical differences among the family members (Table 1 ).

\begin{tabular}{|c|c|c|c|c|c|c|}
\hline Affected individual & Age at diagnosis & Age at institution of dialysis & Age at kidney transplant & Presence of gout & Hypertension & Age at death \\
\hline M & Unknown & - & $\cdot$ & No & Yes & 86 \\
\hline s1 & 47 & 42 & 47 & Yes & Yes & 54 \\
\hline GD1 & 17 & 42 & 44 & Yes & Yes & $\cdot$ \\
\hline GD2 & 16 & 45 & 46 & Yes & Yes & $\cdot$ \\
\hline GD3 & 8 & 33 & 36 & Yes & Yes & $\cdot$ \\
\hline GGD1 & 12 & $\cdot$ & $\cdot$ & No & Yes & $\cdot$ \\
\hline GGGD1 & 12 & - & - & No & No & $\cdot$ \\
\hline
\end{tabular}

TABLE 1: Variable presentations of uromodulin kidney disease in members of a family

M: Mother, S1: son, D1: daughter, GD1/2/3: granddaughter 1/2/3, GGD1: great-granddaughter, GGGD1: great-great-granddaughter

The severity of gout varies greatly from one member to another and some have hyperuricemia without gout. GGD1 is 49-years-old and has not yet required dialysis but her kidney function has declined to the point that she is eligible to be placed on the kidney transplant list. GD1, 2, and 3 all had successful kidney transplants which have effectively cured their hyperuricemia and gout. Since the disease is related to an intrinsic renal cell mutation, kidney transplant cures the disease without possible recurrence. They remain on blood pressure medications to protect the transplanted kidney.

\section{Discussion}

While all three subtypes of ADTKD are rare, $\sim 400$ affected families have been identified in the United States. Early recognition of these patients ensures proper follow-up and management. Clinical suspicion for UKD should be raised in a young person with elevated serum creatinine, hyperuricemia or precocious gout, or hypertension. Due to the absence of hematuria or proteinuria, urinalysis is not helpful in diagnosis. As with any genetic disorder, taking a thorough family history is vital. De novo mutations resulting in UKD are very rare, so patients will usually have a strong family history of gout, chronic kidney disease, or kidney transplants. Patients should be referred for genetic testing to determine the mutations that are involved. Since disease severity, rate of progression, and end-point varies dramatically even among patients within the same family, management is determined on a case by case basis and involves symptomatic treatment. Patients with hyperuricemia or gout are started on allopurinol or febuxostat. Likewise, anemia, hyperphosphatemia, hypertension, and other manifestations of CKD are treated as they arise using the same guidelines as in patients without UKD. Unlike in proteinuric CKD, there has been no evidence that angiotensin converting enzyme inhibitors or angiotensin receptor blockers slow progression of CKD in patients with UKD. There are trials that show slowed progression to ESRD in kidney disease patients when they are started on allopurinol early in the disease course [2]. However, the results were not specific to UKD patients and there have not been adequate trials in this population. While there is variability in age of onset, UKD will almost invariably progress to ESRD. Preemptive renal transplantation in adults is considered when the glomerular filtration rate (GFR) is $<20 \mathrm{~mL} / \mathrm{min} / 1.73 \mathrm{~m} 2$. A renal transplant is considered curative. Dialysis will need to be considered if donor kidney is not available and GFR drops enough that signs and symptoms of kidney failure become apparent (usually Stage 5 CKD) [3].

\section{Conclusions}

Ultimately, genetic diagnosis and eventual renal transplant will happen at an established medical center capable of providing these services, but long-term management will often fall to the primary care physician. Optimal control of hypertension, hyperuricemia, and kidney function will determine a patient's quality of 


\section{Cureus}

life and future development of comorbidities secondary to their diagnosis.

\section{Additional Information}

\section{Disclosures}

Human subjects: Consent was obtained by all participants in this study. Conflicts of interest: In compliance with the ICMJE uniform disclosure form, all authors declare the following: Payment/services info: All authors have declared that no financial support was received from any organization for the submitted work. Financial relationships: All authors have declared that they have no financial relationships at present or within the previous three years with any organizations that might have an interest in the submitted work. Other relationships: All authors have declared that there are no other relationships or activities that could appear to have influenced the submitted work.

\section{References}

1. Bleyer AJ, Hart PS, Kmoch S: Hereditary interstitial kidney disease. Semin Nephrol. 2010, 30:366. 10.1016/j.semnephrol.2010.06.003

2. Siu YP, Leung KT, Tong MK, Kwan TH: Use of allopurinol in slowing the progression of renal disease through its ability to lower serum uric acid level. Am J Kidney Dis. 2006, 47:51-9. 10.1053/j.ajkd.2005.10.006 3. Levin A, Stevens PE, Bilous RW, et al.: Kidney disease: Improving global outcomes (KDIGO) CKD work group. KDIGO 2012 clinical practice guideline for the evaluation and management of chronic kidney disease. Kidney Int Suppl. 2013, 3:1-150. 10.1038/kisup.2012.73 